\title{
SUMMER VENTILATION OF POULTRY HOUSE FOR CHICKEN FATTENING IN CFD MODELLING
}

\author{
Van Doan Cao ${ }^{1}$, Milan Zajicek ${ }^{2}$, Pavel Kic ${ }^{1}$ \\ ${ }^{1}$ Czech University of Life Sciences Prague; ${ }^{2}$ Academy of Science of the Czech Republic \\ caodoan2006@gmail.com,zajicek@utia.cas.cz,kic@tf.czu.cz
}

\begin{abstract}
The aim of this paper is a numerical analysis of ventilation of the buildings for broilers during summer. Ventilation is the most important operation for internal environment to achieve the best performance of chickens. At each stage of growth of the chicken an optimum performance zone exists, in which the chickens use the most of the energy from food for growth. The target temperature for the best performance of broilers during growth changes daily and therefore ventilation is necessary to be modified by a suitable method. During the fattening period the biological production and thermoregulatory ability of chickens change significantly. In summer at the end of the fattening period, the problem of making the internal environment is more significant. The fundamental problem will be solved by using mathematical simulation, and the speed of flow will be determined in the ventilated space. For the research in the airflow, for prediction of the expected speed and air temperatures CFD (computer fluid dynamics) software Fluent was used. The effects of the change of the geometry and outside temperature, the concentration of carbon oxides, ammonia and dust within the hall were also monitored. The examined results of the program Fluent in all variations of temperatures and geometry for the location of the ventilation systems will be compared and then the effects and aftermath within the climatic conditions will be evaluated.
\end{abstract}

Keywords: broiler, Fluent, temperature, ventilation.

\section{Introduction}

Poultry housing technology, external climatic conditions and the weather influence the indoor microclimate during different periods of the year. It requires different methods of ventilation control $[1 ; 2]$. Creation of internal environment in the halls for poultry housing is complicated mainly because of the high biological load of indoor environment, resulting from the large number of chickens per 1 $\mathrm{m}^{2}$ of the floor area. Problems occur particularly towards the end of fattening. Chickens have a large mass; they produce large quantities of pollutants [2;3]. Usually this problem is solved by intensive ventilation [4; 5], but it has a rather negative influence also on the technical equipment [6].

The target temperature best for broilers during their growth varies and depends on the size of the chicken and other factors. This is usually around $30^{\circ} \mathrm{C}$, the lowest temperature on the first days is nearly $20^{\circ} \mathrm{C}$ or less at the time of slaughter [7]. Therefore, ventilation must be adjusted by the corresponding method to maintain the optimal temperature.

The perceived temperature by the chicken depends on humidity. If the relative humidity is out of the ideal range of 60 to $70 \%$, the temperature within the hall needs to be adjusted. For example, if RH is near $50 \%$, the temperature has to be increased to $33^{\circ} \mathrm{C}$ on the first day[8]. In all stages of growth of the chicken we have to observe and ensure that chickens perceive appropriate temperature [9].

Ventilation is the only practical way to reduce very high humidity, which is the most common problem in winter and it can affect the health of the chicken. Even when ventilation is not necessary used to remove heat, it can be maintained at minimum level to prevent wetting, hardening, bedding and problems with ammonia [10].

While breathing, chickens receive oxygen from the air and exhale carbon dioxide. Therefore, it is necessary to supply fresh air to exchange oxygen and remove the excess of carbon dioxide. Ventilation is necessary to provide fresh air during the year in warm and cold weather. The most common problem of the air quality is ammonia, which is caused by the very wet bedding. This causes health problems. Correct ventilation prevents the accumulation of ammonia by controlling the relative humidity [11].

The Fluent CFD software is used as a universal tool for numerical analysis of fluid flow and thermal analysis. The influence of the geometrical shape and the velocity field on the thermal field was also monitored .Effective distribution of fresh air inside the building and the corresponding locations of inlets and exhaust outlets contribute to the effectiveness of the ventilation components. The thermal analysis also dealt with extreme temperature conditions inside the interior during a partial and complete failure of the ventilation system and leads to evaluation of the effect and consequences of indoor microclimatic conditions [12]. 


\section{Materials and methods}

This research work and measurements were carried out in a building for fattening of broilers. The poultry house has internal dimensions: length $100 \mathrm{~m}$, width $11.5 \mathrm{~m}$, height $2.7 \mathrm{~m}$, and the inside hall is housing 23,000 chickens on the floor. The measurements were carried out during the $26^{\text {th }}$ to $33^{\text {rd }}$ days of fattening when the chicken have average weight about $1.5 \mathrm{~kg}$.

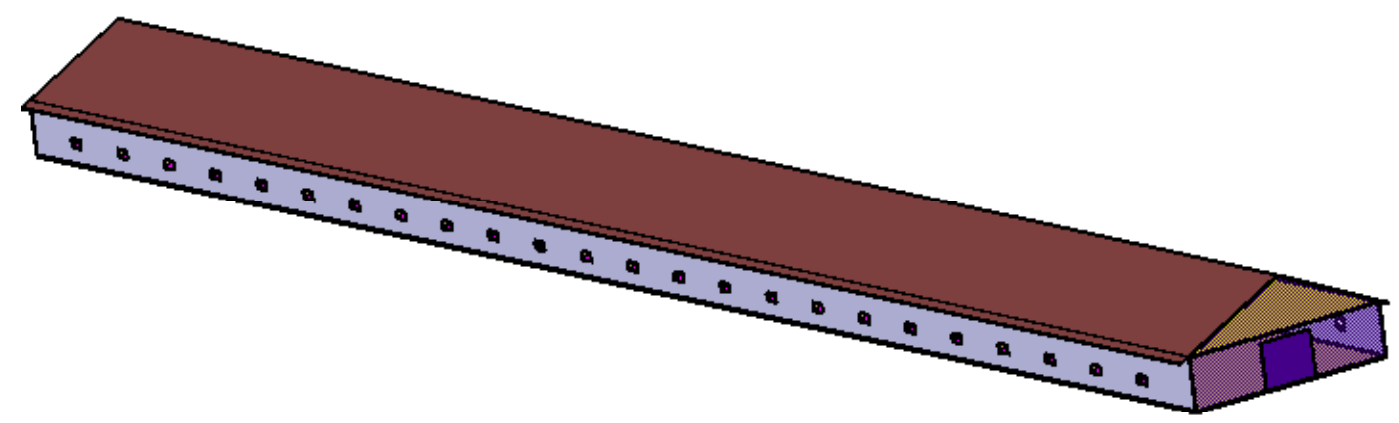

Fig. 1. 3D modeling of the experimental hall

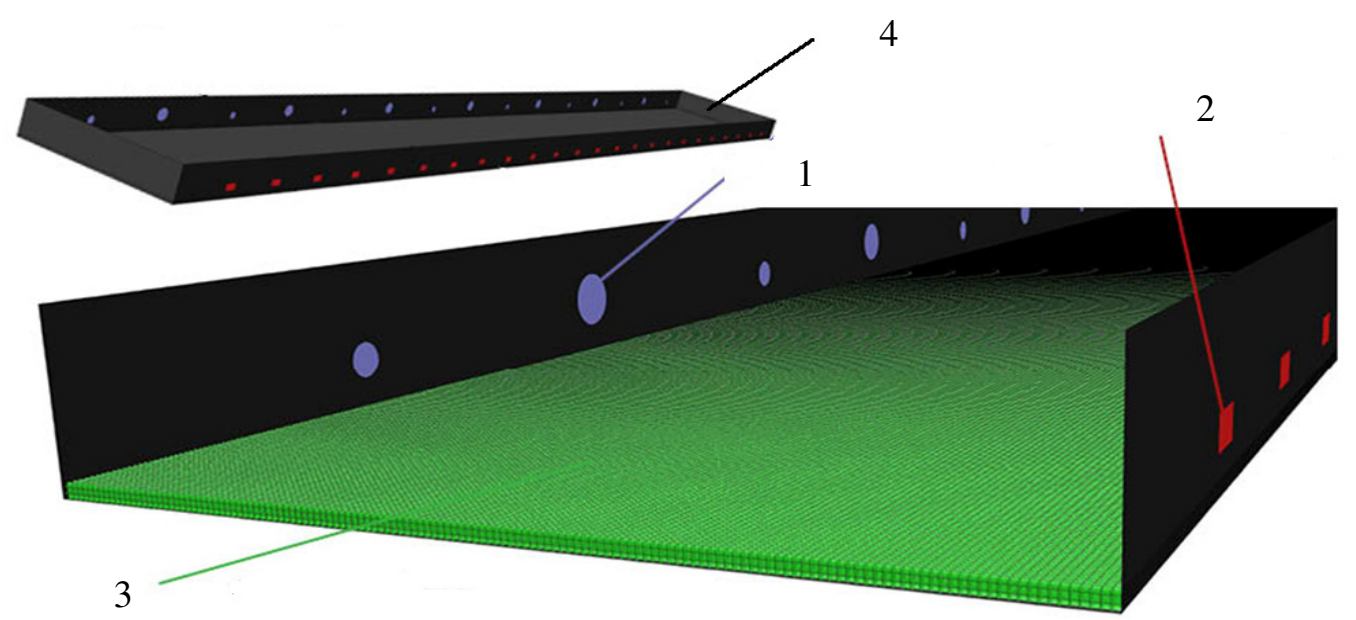

Fig. 2. Computational mesh and boundary condition zones: 1 - exhaust fan; 2 - window;

3 - slice volume; 4 - computational domain

Fig. 1 shows the actual shape of the hall that is simulated by graphic software CATIA with the structure and size equivalent to the fact. Because the ceiling of the hall has a flat shape, the space of the hall can be considered a cube. Input data for the program Fluent have to be made of the surface and closed space, therefore, the inside space was split with the corresponding position of the windows and fans. Beside graphical data, we should add more data to the program, e.g., the temperature outside, humidity of the air, the thermal conductivity of the wall, the heat production of chickens (can be considered as the exothermic of the floor).

Fluent CFD software was used as a computational tool to obtain the numerical solution of the flow, temperature and concentration profiles corresponding with the measurement. Two sets of boundary conditions were prepared to illustrate the difference between the transversal and longitudinal ventilation, mainly with respect to maximal values of velocities, temperatures and pollutant concentrations.

Fig.2 shows the simplified shape of the computational domain. It can be seen, that it is a pure geometrical block with rectangular windows on the right side and circular fans on the opposite left side. The most important simplification relative to the actual state is the usage of the $0.2 \mathrm{~m}$ tall "Slice volume", which is the zone, where animals move and produce heat and pollutants. The main reason for using this auxiliary volume is a possibility to include heat and mass sources to the volume in values per cubic meter. This attempt is closer to the reality than using only the surface source (values per square meter). For example: usage of the heat surface source from the floor representing the 
amount of the heat flow produced by animals leads to unreal overheating of the floor and therefore it cannot be recommended for this kind of problems.

\section{Results and discussions}

Calculation of the required air flow:

$$
m_{v \max }=b \cdot m_{z}^{d} \cdot 10^{-3}
$$

where $m_{v \max }-$ doses of ventilation air for 1 animal, $\mathrm{kg} \cdot \mathrm{s}^{-1} \cdot \mathrm{pcs}^{-1}$;

$m_{z}$ - weight of one animal, $\mathrm{kg} \cdot \mathrm{pcs}^{-1}$;

$b, d$-constants determined for each piece from the table.

$$
M_{v \max }=Z \cdot m_{v \max },
$$

where $M_{v \max }-$ total air flow, $\mathrm{kg} \cdot \mathrm{s}^{-1}$;

$Z$ - quantity of animals, pes.

$$
V_{a}=\frac{M_{v \max }}{\rho},
$$

where $V_{a}$ - volumetric air flow, $\mathrm{m}^{3} \cdot \mathrm{h}^{-1}$

$\rho$ - density of air, $\mathrm{kg} \cdot \mathrm{m}^{-3}$.

With the capacity of the large fan $0.75 \mathrm{~kW}$ or $24,929 \mathrm{~m}^{3} \cdot \mathrm{h}^{-1}$ and of the small fan $0.33 \mathrm{~kW}$ or $7,024 \mathrm{~m}^{3} \cdot \mathrm{h}^{-1}$, we can choose the quantity of the fans to activate.

Table 1

Parameters and number of required fans used according to calculation results

\begin{tabular}{|c|c|c|c|}
\hline States of chickens & $\begin{array}{c}\text { Volumetric air } \\
\text { flow, } \mathbf{~ m}^{\mathbf{3}} \cdot \mathbf{h}^{\mathbf{- 1}}\end{array}$ & $\begin{array}{c}\text { Quantity of large } \\
\text { fans, pcs }\end{array}$ & $\begin{array}{c}\text { Quantity of small } \\
\text { fans, pcs }\end{array}$ \\
\hline $\begin{array}{c}26^{\text {th }} \text { day of fattening } \\
\mathrm{m}_{\mathrm{z}}=1.5 \mathrm{~kg} \cdot \mathrm{pcs}^{-1}\end{array}$ & 172,040 & 5 & 2 \\
\hline $\begin{array}{c}35^{\text {th }} \text { day of fattening } \\
\mathrm{m}_{\mathrm{z}}=2.1 \mathrm{~kg} \cdot \mathrm{pcs}^{-1}\end{array}$ & 214,140 & 7 & 6 \\
\hline Total fans in the hall & 230,000 & 7 & 8 \\
\hline
\end{tabular}

The input data for the CFD program:

- Construction data;

- Outside temperature: $t=21.6^{\circ} \mathrm{C}$;

- Outside concentration $\mathrm{CO}_{2}: 0.04 \%=400 \mathrm{ppm}$;

- Production of $\mathrm{CO}_{2}$ on the floor: $0.065 \mathrm{~g} \cdot \mathrm{s}^{-1} \cdot \mathrm{m}^{-3}$;

- Production heat of chickens: $Q_{c}=74.6 \mathrm{~W} \cdot \mathrm{m}^{-2}$;

- Heat transfer coefficient through the composite wall and ceiling: $\mathrm{k}=0.773 \mathrm{~W} \cdot \mathrm{K}^{-1} \cdot \mathrm{m}^{-2}$.

The presented results arise directly from the measured values and the total flow rate is the same for both basic configurations.

Basic result visualization can be seen in Fig. 3 as mass concentration of ammonia in case of transversal ventilation and in Fig.4 it compares the velocity profile of the longitudinal and transversal ventilation. The overall flow rate is the same for both variants and it leads to clear consequence, that for the smaller cross section area during the longitudinal ventilation the velocities are higher than during the transversal one. It is clearly seen, that the flow during the transversal ventilation is very fluctuating, with the repeating velocity pattern shapes corresponding to the position of the windows and fans. It has to be said that the pattern shown here is the only one of a lot of possibilities obtained as a steady state solution. Nature of the flow is in this case given by the considerable number of inputs and outputs and it is understood that in actual case the pattern can make time dependent changes in the shape of particular air streams. The longitudinal ventilation leads to smooth flow with steady velocity profile. 


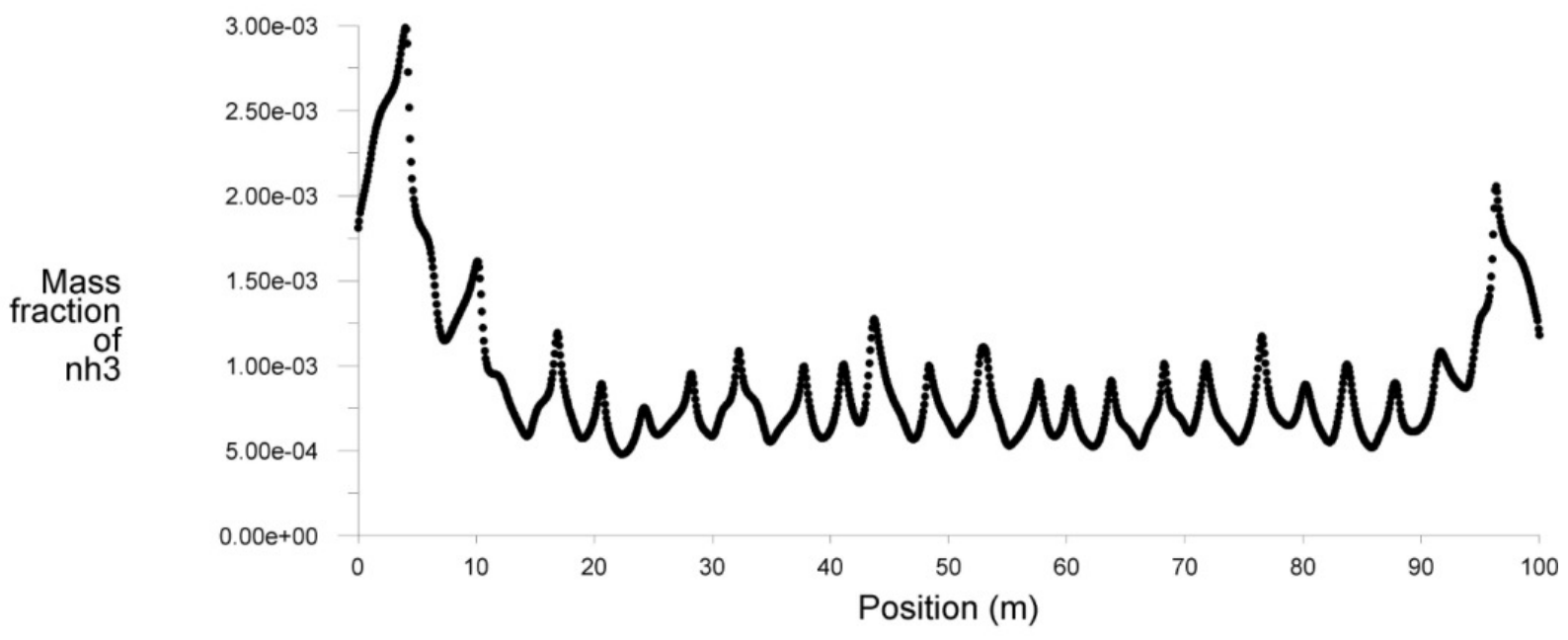

Fig. 3. Mass fraction of $\mathbf{N H}_{3}$ in case of transversal ventilation

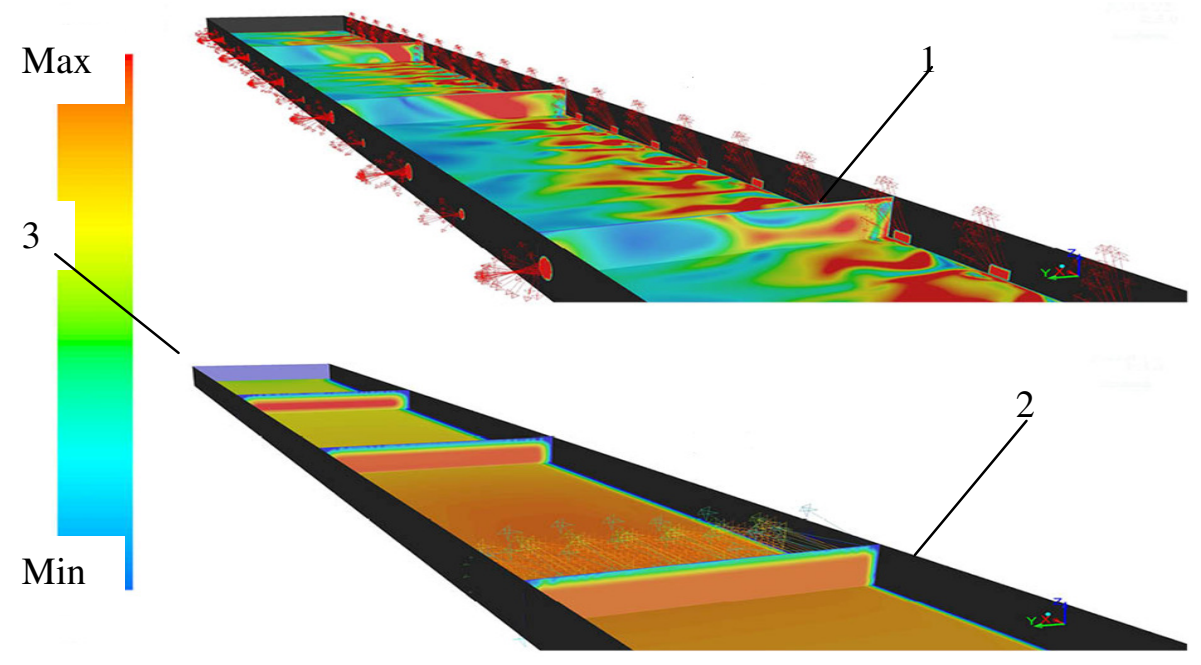

Fig. 4. Comparison of flow pattern for transversal and longitudinal ventilation: $1-$ transversal ventilation: $\min =0 \mathrm{~m} \cdot \mathrm{s}^{-1}, \max =1.6 \mathrm{~m} \cdot \mathrm{s}^{-1} ; 2-$ longitudinal ventilation: $\min =2 \mathrm{~m} \cdot \mathrm{s}^{-1}$, $\max =2.7 \mathrm{~m} \cdot \mathrm{s}^{-1} ; 3-$ level of velocity

The more accurate view into the results of CFD can be done by visualization of the results in form of graphs. Fig. 5 shows the comparison of transversal and longitudinal ventilation at the same profile, which is defined as a central axis of the stable at the height $0.5 \mathrm{~m}$ above the floor. It can be seen that in the case of transversal ventilation the existence of poorly ventilated areas at the front and the end of the broiler house exists, because the concentration of pollutants rapidly grows. The longitudinal ventilation makes the ventilation more uniform, but the animals at the end of the hall are permanently at higher concentration of pollutants in comparison with those, who live in the front of the stable.

The dust concentration was measured, but the models which were tried to use and solve in Fluent for the presented flow conditions lead to results with completely nonsense values of concentration and dust distributions. The Fluent mixture model was used [13], but it was not practically possible to archive the convocation to measured values in the stationary state in such large geometry. Therefore, the dust simulation is not presented here and will be tested at smaller models to obtain a functional methodology at first and will be the subject of the forthcoming research. 

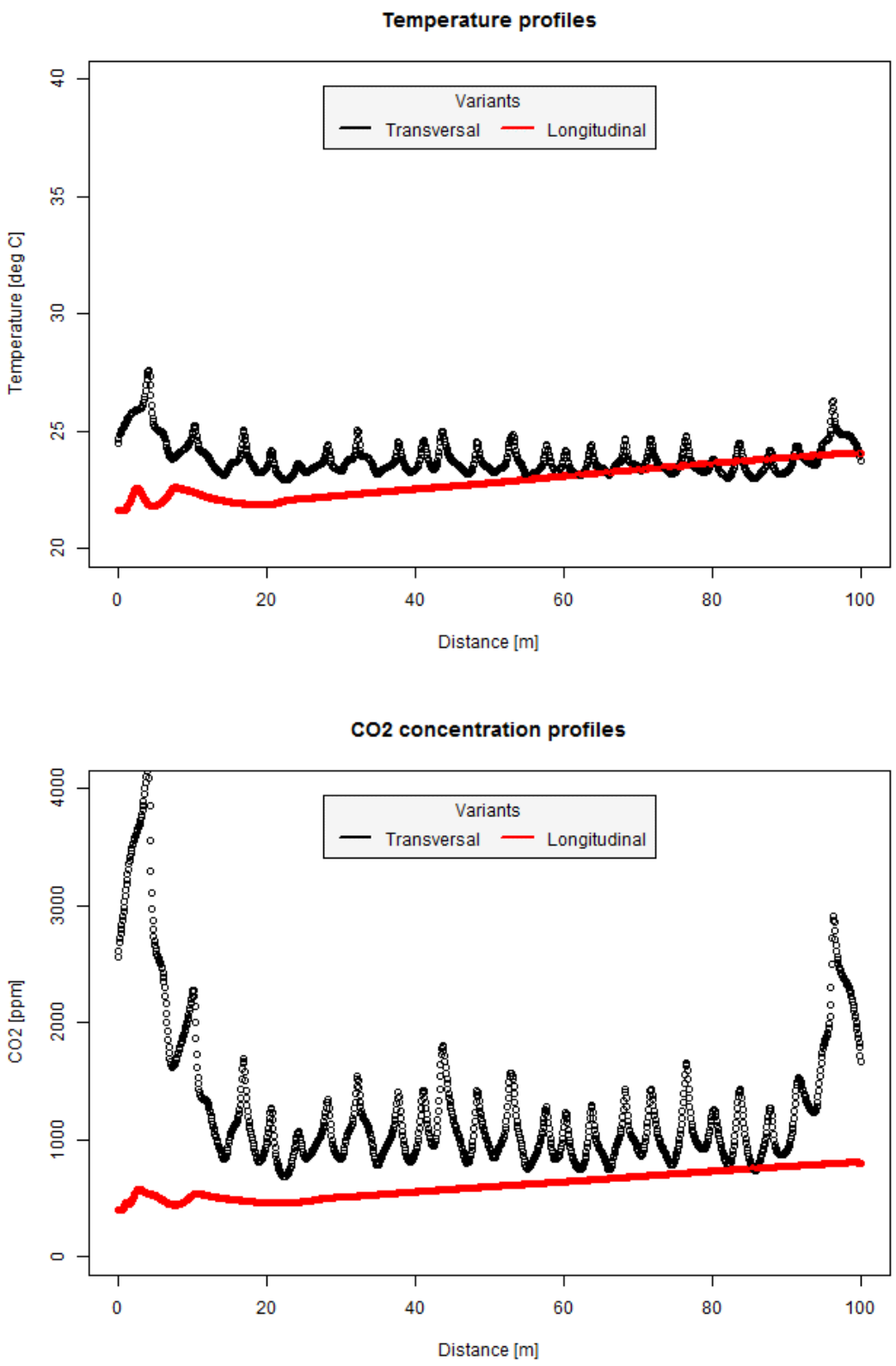

Fig. 5. Comparison of temperature and $\mathrm{CO}_{2}$ mass fraction in central axis of the stable at the height $0.5 \mathrm{~m}$ above the floor

\section{Conclusions}

1. It is possible to calculate the necessary flow of air for chickens in several age and weight categories and check the suitable fans for effective ventilation rate.

2. The longitudinal ventilation makes more uniform temperature and concentration of $\mathrm{CO}_{2}$, and more efficient convective cooling effect during hot summer ventilation, but at the end of the hall, concentration of pollutants is always higher than at the front of the hall.

3. Computer fluid dynamic as a simulation tool can bring obvious and clear benefit because of the possibility to compare the variants of the solution including ventilation defects and failures. From this point of view, it can be very helpful for increasing the quality of ventilation control and regulation.

4. It is possible to continue to use CFD to simulate in the winter conditions when outdoor temperatures are low and inside the hall heating systems for habitat are used or it can be used for more complex and more difficult cases. 


\section{Acknowledgement}

Access to computing and storage facilities owned by parties and projects contributing to the National Grid Infrastructure MetaCentrum provided under the program "Projects of Large Research, Development, and Innovations Infrastructures" (CESNET LM2015042), is greatly appreciated.

\section{References}

1. Kic P., Hubený, M., Ledvinka Z., Tůmová E., Campos C.G., Martínez C.T. Control of indoor environment in housing of laying hens. Proceedings of International conference "Trends in Agricultural Engineering", 2007, CULS, Prague, pp. 212-214.

2. Kic P., Růžek L., Ledvinka Z., Zita L., Gardiánová I. Pollution of indoor environment in poultry housing. Proceedings of International conference 11th International Scientific Conference "Engineering for Rural Development", Latvia University of Agriculture, 2012, Jelgava, pp. 480483.

3. Aarnink A.J.A., Van Harn J., Winkel A., De Buisonje F.E., Van Hattum T.G., Ogink N.W.M. Spraying rapeseed oil reduces dust in poultry houses. Proceedings of International conference "Precision Livestock Farming 2009", 4th European Conference on Precision Livestock Farming, ECPLF, 2009, Elsevier, Wageningen, pp. 73-79.

4. Šottník J. Principles and experience of heat stress reduction in buildings for housing of animals. Proceedings of International conference "Trends in Agricultural Engineering", 2007, CULS, Prague, pp. 441-446.

5. Zajíček M., Kic P. Longitudinal ventilation of broiler house - simulation of variants. Proceedings of International conference 12th International Scientific Conference "Engineering for Rural Development", 2013, Latvia University of Agriculture, Jelgava, pp. 198-202.

6. Kic P., Kalvoda M., Zavadil V. Energy savings byheat recovery in ventilation. Proceedings of International conference "Trends in Agricultural Engineering", 2007, CULS, Prague, pp. 215-218.

7. Henriksen S., Bilde T., Riber A.B. Effects of post-hatch brooding temperature on broiler behavior, welfware, and growth. Poultry Science, Volume 95, Issue 10, 1 October 2016, pp. 22352243

8. De Basilio V., Requena F., Leon A., Velazco Z., Picard M. Does early thermal conditioning sometimes fail to improve the resistance of broilers to heat stress? Animal Research, Volume 51, Issue 5, 2002, pp. 407-420.

9. Said, J., Bod'o, S., Saady, T., Galik, R., Sardary, S., Abbas, K. Effect of broler chickens loving conditions on results of fattening. Agronomy Research,Volume 14, Issue 1, 2016, pp. 228-235.

10. Purswell J.L., Dozier III W.A., Olanrewaju H.A., Davis J.D., Xin H., Gates R.S. Effect of temperature-humidity index on live performance in broiler chickens grown from 49 to 63 days of age. Proceedings of International conference 9th International Livestock Environment Symposium, 2012, Valencia, Spain, 8 July 2012 through 12 July 2012,code 97164,pp. 41-49.

11. Liu W., Cheng P., Wang Z., Ma W. Effect of rice peptides on the performance, health condition of broler and ammonia concentration in henhouse. Journal of the Chinese Cereals and Oils Association,Volume 28, Issue 12, December 2013, pp. 82-85.

12. Zajíček M., Kic P. Simulation of the broiler house ventilation. Scientia agriculturae bohemica, vol. 44(1), 2013, pp. 32-37.

13. The limitations apply to the mixture model in Fluent. [online][20.03.2017] Available at: https://www.sharcnet.ca/Software/Fluent6/html/ug/node891.htm 